\title{
Memory CD8T cells specific for Plasmodia liver-stage antigens maintain protracted protection against malaria
}

\section{Urszula Krzych*, Sarat Dalai ${ }^{\dagger}$, Stasya Zarling ${ }^{*}$ and Alexander Pichugin}

Department of Cellular Immunology, Branch of Military Malaria Vaccine Development, Walter Reed Army Institute of Research, Silver Spring, MD, USA

\section{Edited by:}

Gabrielle Belz, Walter and Eliza Hall

Institute of Medical Research,

Australia

\section{Reviewed by:}

John Harty, University of lowa, USA William R. Heath, The University of

Melbourne, Australia

\section{*Correspondence:}

Urszula Krzych, Department of Cellular Immunology, Building 503

Forest Glen Annex, Walter Reed Army Institute of Research, Silver Spring, $M D, U S A$.

e-mail: urszula.krzych1@us.army.mil

\section{${ }^{\dagger}$ Present address:}

Sarat Dalai, Institute of Science, Nirma University,

Sarkhej-Gandhinagar Highway,

Ahmedabad, India.

${ }^{\ddagger}$ National Research Council Fellow.
Immunologic memory induced by pathogenic agents or vaccinations is inextricably linked to long-lasting protection. Adequately maintained memory $T$ and $B$ cell pools assure a fast, effective, and specific response against re-infections. Studies of immune responses amongst residents of malaria endemic areas suggest that memory responses to Plasmodia antigens appear to be neither adequately developed nor maintained, because persons who survive episodes of childhood malaria remain vulnerable to persistent or intermittent malaria infections. By contrast, multiple exposures of humans and laboratory rodents to radiation-attenuated Plasmodia sporozoites ( $\gamma$-spz) induces sterile and long-lasting protection against experimental sporozoite challenge. Protection is associated with $\mathrm{MHC}$-class I-dependent CD8T cells, the key effectors against pre-erythrocytic stage infection. We have adopted the P. berghei $\gamma$-spz mouse model to study memory CD8 T cells that are specific for antigens expressed by Pb liver-stage (LS) parasites and are found predominantly in the liver. On the basis of phenotypic and functional characteristics, we have demonstrated that liver CD8T cells form two subsets: $\mathrm{CD} 44^{\mathrm{hi}} \mathrm{CD} 62 \mathrm{~L}^{\text {lo }} \mathrm{KLRG}-1^{+} \mathrm{CD} 107^{+} \mathrm{CD} 127^{-} \mathrm{CD} 122^{\mathrm{lo}} \mathrm{CD} 8$ $\mathrm{T}$ effector/effector memory ( $\mathrm{T}_{\mathrm{E} / \mathrm{EM}}$ ) cells that are the dominant IFN- $\gamma$ producers and

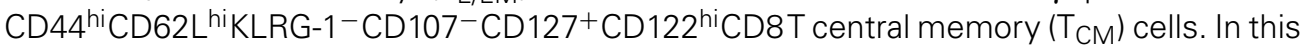
review, we discuss our observations concerning the role of $\mathrm{CD}_{8} \mathrm{~T}_{\mathrm{E} / \mathrm{EM}}$ and $\mathrm{CD} 8 \mathrm{~T}_{\mathrm{CM}}$ cells in the maintenance of protracted protective immunity against experimental malaria infection. Finally, we present a hypothesis consistent with a model whereby intrahepatic CD8 $\mathrm{T}_{\mathrm{CM}}$ cells, that are maintained in part by LS-Ag depot and by IL-15-mediated survival and homeostatic proliferation, form a reservoir of cells ready for conscription to $C D 8 T_{E / E M}$ cells needed to prevent re-infections.

Keywords: memory T cells, malaria, Plasmodium, liver, IL-15, CD8T cells, mouse model

\section{INTRODUCTION}

One of the cardinal features of Ag-specific immune responses elicited by infections or vaccinations is the persistence of optimally effective memory $\mathrm{T}$ cells that are inextricably linked to longlasting protection (Ahmed and Gray, 1996). Adequately maintained memory $\mathrm{T}$ cells assure a fast, effective, and specific response against reoccurring infections. Studies of protective immunity amongst residents of malaria endemic areas indicate that protective immunity to Plasmodia antigens develops gradually after multiple exposures over many years and, although associated with a decline in clinical manifestations of the disease, it decays rapidly once exposure to the parasite ceases (Langhorne et al., 2008). However, it is not clear why protection does not persist after malaria infection. We hypothesized (Krzych et al., 2000) that the absence of adequately developed immunologic memory, which stems from the tolerant milieu of the liver (Crispe, 2011), sequestration of the liver-stage antigens (LS-Ags) within hepatocytes, and relatively short duration of the liver-phase infection, is mainly responsible for the lack of lasting protection. Others suggested that a phenomenon known as altered peptide ligand, resulting from polymorphisms at CD8 $\mathrm{T}$ cell sites, induces antagonistic effects that interfere with the priming and the survival of memory $\mathrm{T}$ cells (Plebanski et al., 1999). Poor immunogenicity may also stem from inadequate immunizing doses or immunologic interferences from blood-stage parasites (Good et al., 2005; Urban et al., 2005). Interestingly, currently conducted studies with the RTS,S vaccine, which is based on Plasmodium falciparum circumsporozoite protein (CSP), indicate that protection is conferred to infants and small children but it lasts for a relatively short period of time (Abdulla et al., 2008).

In contrast, exposure of laboratory rodents (Nussenzweig et al., 1967), monkeys (Nussenzweig et al., 1970), and humans (Clyde et al., 1973) to radiation-attenuated $(\gamma)$ Plasmodia sporozoites $(\gamma$-spz) induces sterile and long-lasting protection. Plasmodia $\gamma$-spz-induced protection is multifactorial (Nardin and Nussenzweig, 1993), involving antibody (Egan et al., 1993), CD4 (Nardin et al., 1989), and CD8 T cell (Wizel et al., 1995) responses directed primarily to CSP. However, blood-stage antigens also recall IL-4 producing memory CD4 T cells in protected subjects (Palmer and Krzych, 2002) and LS antigen-1- (LSA-1) specific proliferative T cell responses correlate with protection (Krzych et al., 1995).

CD8 T cells have been considered key effectors against preerythrocytic stage infection. Evidence supporting the effector function of CD8 T cells is based on studies in human (Malik 
et al., 1991) and animal (Schofield et al., 1987; Weiss et al., 1988; Berenzon et al., 2003) models of $\gamma$-spz-induced protection, protection induced by genetically attenuated parasites (GAP) (Jobe et al., 2007; Mueller et al., 2007; Tarun et al., 2007; Trimnell et al., 2009) as well as on more recent observations made in models of protection induced by wild type Plasmodia sporozoites administered under drug coverage (Nganou-Makamdop et al., 2012). Studies conducted in malaria endemic areas confirm the involvement of effector CD8 T cells in protection (Bejon et al., 2007). The effector function is associated mainly with the production of inflammatory cytokines such as IFN- $\gamma$ or TNF- $\alpha$ that mediate elimination of the parasite within the hepatocytes by the nitric oxide (NO) pathway (Seguin et al., 1994). CD8 T cells also exhibit cytolytic activity against targets that express antigens belonging to pre-erythrocytic stage parasites (Hill et al., 1991; Malik et al., 1991; Trimnell et al., 2009).

Our lab has adopted the P. berghei $\gamma$-spz ( $\mathrm{Pb} \gamma$-spz) mouse model to study memory CD8 T cells against experimental malaria infection. CD8 $\mathrm{T}$ cells that arise in $\mathrm{Pb} \gamma$-spz-immunized $\mathrm{B} 6$ mice are specific for antigens expressed by the developmentally aborted LS parasites (Berenzon et al., 2003) and antigen experienced CD44 ${ }^{\text {hi }} \mathrm{CD} 8 \mathrm{~T}$ cells are found predominantly in the liver (Guebre-Xabier et al., 1999). In this review, we mainly focus on memory CD8 $\mathrm{T}$ cells in the maintenance of protracted protection in the $\mathrm{Pb} \gamma$-spz model. We also comment on studies in other model systems of sterile protection that extend our hypothesis by demonstrating the necessity for late LS-Ags and the induction of effector and memory CD8 $\mathrm{T}$ cells for lasting protection (Butler et al., 2011; Teirlinck et al., 2011). We hypothesize that long-term protection to pre-erythrocytic stage infection can be induced and maintained. As such, it requires the formation and persistence of a central memory $\left(\mathrm{T}_{\mathrm{CM}}\right) \mathrm{CD} 8 \mathrm{~T}$ cell reservoir, which is maintained in part by LS-Ag depot and by IL-15 and which gives rise to IFN- $\gamma$ producing effector/effector memory $\left(\mathrm{T}_{\mathrm{E} / \mathrm{EM}}\right) \mathrm{CD} 8 \mathrm{~T}$ cells during re-infections.

\section{PLASMODIA PARASITES IN THE MAMMALIAN HOST; THE IMPORTANCE OF THE LIVER-STAGE}

Plasmodia sporozoites are inoculated into a mammalian host from the salivary glands of an Anopheles mosquito during its blood meal. Sporozoites then quickly travel to the liver via the circulatory and/or lymphatic systems. In the liver, sporozoites undergo further development before they emerge as blood-stage merozoites that infect the red blood cells. Hence, in the mammalian host the Plasmodium parasite exhibits three morphologically distinct phases of development: sporozoite-, liver-, and blood-stage. During each stage, the parasite expresses, to some extent, unique protein profiles. The sporozoite-associated proteins facilite parasite invasion of hepatocytes (Rogers et al., 1992; Frevert, 1994; Robson et al., 1995; Fidock et al., 1997) and, under certain conditions, are potent antigens for the induction of cellular and antibody responses. For example, CSP-specific responses correlate with protection in humans (Hoffman et al., 2002) and mice (Schofield et al., 1987). LS-Ags are expressed by the developing parasite within the parasitophorous vacuole in hepatocytes (Mueller et al., 2005; Prudencio et al., 2006) and they are considered to be the major inducers of protective cellular immune responses against the pre-erythrocytic stage parasite (Fidock et al., 1994; Bucci et al., 2000). Proteins that characterize the erythrocytic stage are thought to play a role in the invasion of red blood cells (Holder, 1996).

The mammalian liver plays a key role in the life cycle of the Plasmodium parasite as the LS is not only pivotal for survival of the parasite, but it also represents a significant period for the induction, effector phase, and the maintenance of immune memory responses. Understanding immune events that occur in the liver in model systems of protective immunity, as well as during natural infection, will expand our knowledge of organ-specific immune responses to Plasmodia antigens and hence facilitate exploitation of these responses to expedite progress in vaccine development against this serious disease.

\section{A MODEL OF PROTRACTED PROTECTION INDUCED BY PLASMODIA $\gamma-S P Z$}

Plasmodia $\gamma$-spz-induced sterile and protracted protection is considered the gold standard of anti-malaria vaccines. Like infectious sporozoites, $\gamma$-spz carrying CSP and other sporozoite-associated proteins, invade the liver where they undergo aborted development and express LS-Ags (Zechini et al., 1999; Hollingdale and Krzych, 2002). It is believed that antigens expressed by the underdeveloped liver schizonts remain in the liver forming a LS-Ag depot (Scheller and Azad, 1995), which is critical for induction and persistence of Ag-specific protracted protective immunity (Krzych et al., 2000). Treatment of animals with primaquine, a drug which disrupts LS development, concurrently with the $\gamma$-spz-immunizations abolishes lasting protection (Scheller and Azad, 1995; Berenzon et al., 2003).

The prevailing state of tolerance in the liver allows for infectious sporozoites to expand and continue their life cycle. However, immunization with $\gamma$-spz reverses this tolerance to inflammation, which is needed for the induction as well as persistence of adaptive immune responses (Krzych, 1999). Before the invasion of hepatocytes, $\mathrm{Pb} \gamma$-spz, like infectious sporozoites, pass through Kupffer cells (KC) (Pradel and Frevert, 2001) changing them to become high IL-12 producers (Steers et al., 2005). In contrast, infectious sporozoites do not activate naïve KC to produce IL-12, and instead downregulate IL-10 (Steers et al., 2005). The importance of IL12 was demonstrated as an inducer of IFN- $\gamma$ and iNOS (Sedegah et al., 1994; Seguin et al., 1994) and as a critical cytokine for the development of CD8 T cell responses to pre-erythrocytic stage malaria (Doolan and Hoffman, 1999).

The molecular form of the sporozoites might influence the mode of sporozoite entry into $\mathrm{KC}$, which, in turn, might dictate intracellular localization of sporozoites, as has been recently shown for DC interacting with other parasites (Cervi et al., 2004). On the basis of in vitro conducted studies (Pradel and Frevert, 2001; Silvie et al., 2004), the entry of infectious sporozoites is mediated by membrane:membrane fusion and parasites localize in a vacuole that does not co-localize with lysosomes so that sporozoites avoid metabolic degradation before reaching hepatocytes. Conceivably, $\gamma$-spz could be internalized by phagocytosis and channeled to phagosomes for metabolic degradation and export by MHC-class II and I molecules. A significant upregulation of MHC-class I is evident on $\mathrm{KC}$ after sporozoite challenge of $\gamma$-spz-immune mice. In sharp contrast, MHC-class I molecules are downregulated 
on $\mathrm{KC}$ during infection of naïve mice and their APC function is severely reduced (Steers et al., 2005). Inflammatory cytokines increase the expression of MHC-class I-peptide complexes on APC by inducing immune proteosomes for more efficient generation of antigenic peptides for entry into the ER and loading onto empty MHC-class I molecules (Khan et al., 2001). Accordingly, KC from $\gamma$-spz-immune/challenged mice present peptides and protein antigens to specific T cells. We propose that a cascade of pro-inflammatory cytokines released during the innate immune response induced by $\gamma$-spz leads to temporary local inflammation, which is perceived as a "danger signal" needed to trigger proper responses from the adaptive immune system and lead to long-lasting immune memory (Matzinger, 1994).

\section{CD8 T CELLS MEDIATE PROTECTIVE IMMUNITY}

Work based on in vivo depletion of CD8 T cells (Weiss et al., 1988) unequivocally established CD8 T cells as key effectors in a rodent model of protection against malaria. We confirmed these results by demonstrating a failure to protect $\beta_{2}$ microglobulin knockout $\left(\beta_{2} \mathrm{~m} \mathrm{KO}\right)$ mice (White et al., 1996) and $\mathrm{K}^{\mathrm{b}} \mathrm{D}^{\mathrm{b}} \mathrm{KO}$ mice (Krzych and Schwenk, 2005) immunized with $\mathrm{Pb} \gamma$-spz. Protection induced by GAP spz is also CD8 T cell dependent as shown by us in $\beta_{2} \mathrm{~m} \mathrm{KO}$ mice immunized with Pb GAP spz (Jobe et al., 2007) and by others in Py GAP protected mice after depletion of CD8 T cells (Trimnell et al., 2009). We also established that effector CD8 T cells are MHCclass I-restricted/dependent because protection is not transferred by $\gamma$-spz-immune wt cells into $\beta_{2} \mathrm{~m} \mathrm{KO}$ recipients as CD8 T cells must recognize LS-Ag peptides presented by MHC-class I on APC in the liver. The necessity for cognate peptide recognition by CD8 $\mathrm{T}_{\mathrm{E}}$ cells was confirmed in experiments using MHC-class I mismatched effector and target hepatocytes (Chakravarty et al., 2007). The need for proximity between effector lymphocytes and target hepatocytes was demonstrated (Rodrigues et al., 1992), as has the ability of hepatocytes to present CSP to CD8 T cells (Bongfen et al., 2007). Target LS-Ags that induce CD8 T cells are being currently defined by us, as well as others (Doolan et al., 2003), using the combination of genomic and proteomic approaches. For example, targeted gene deletion reveals that Plasmodium sporozoite low-complexity asparagine-rich protein is essential for early LS development (Aly et al., 2011), whereas FabB/F gene (Vaughan et al., 2009) is essential for late-LS development. Immunization of mice with GAP spz with deletions of each of these genes induces protective immunity. Interestingly, immunization with the latearresting fabb/ $\mathrm{f}^{-}$parasites induces durable protection in several mouse strains and across Plasmodia species, presumably because these parasites express a broader repertoire of potential antigens that activate a wider spectra of effector T cells (Butler et al., 2011).

The initial site of induction of liver-resident CD8 T cells remains unclear. It is possible that these cells arise in the liver after interaction with liver APC such as KC or DC that present LS-Ags from developmentally aborted parasites. In support of this hypothesis, we have observed that the number of $\mathrm{cCD} 8 \alpha^{+} \mathrm{DC}$ increases in the liver concurrently with the number of $\mathrm{Pb} \gamma$-spz immunizations, while those in the spleen do not change. Additionally, liver $\mathrm{CDC}$ are very efficient at inducing CD8 $\mathrm{T}_{\mathrm{E} / \mathrm{EM}}$ phenotype and expression of IFN- $\gamma$, a process that is both MHC-class Iand IL-12-dependent (Jobe et al., 2009). The possibility of local activation of CD8 T cells by LS-Ags is quite attractive for several reasons, but especially because it enables a rapid response during re-infection. Although it has been shown that activated CD8 T cells home to the liver to be eliminated as a way of purging their destructive effector mechanism (Mehal et al., 1999), there is also evidence that direct activation of naïve CD8 T cells occurs in the liver (Bertolino et al., 2001; Klein and Crispe, 2006). Alternatively, CD8 T cells might be induced in a draining LN by LS-Ag-loaded DCs and during sporozoite challenge migrate to the liver, where they might undergo further expansion. Although quite attractive, migratory DC do not normally express the $\mathrm{CD} 8 \alpha^{+}$phenotype (Belz et al., 2004) and the $\mathrm{cCD} 8 \alpha^{+}$DC are the major activators of CD8 T cells in our system (Jobe et al., 2009). Although lack of firm evidence supporting either scenario favors the prevailing view that $\mathrm{T}$ cell activation occurs as a result of interaction with $\mathrm{DC}$ in the LN, the possibility of an organ-specific activation of CD8 T cells remains very attractive and should be explored further.

The development of TCR transgenic CD8 T cells specific for the P. yoelii CSP immunodominant peptide SYVPSAEQI (CS-Tg) has enabled the tracking of early immune responses (Sano et al., 2001). After exposure to bites from Py $\gamma$-spz infected mosquitoes, IFN- $\gamma$ producing CS-Tg T cells were detected in the skin draining LN as early as $48 \mathrm{~h}$ after immunization, while spleen and liver responses were not detected until $72 \mathrm{~h}$ (Chakravarty et al., 2007). According to these results, CD8 $\mathrm{T}_{\mathrm{E}}$ cells are generated in the draining LN near the infection (site of mosquito bite) (Chakravarty et al., 2007), and then migrate to liver to kill infected hepatocytes, a process that has been shown to be TAP-dependent, but endosome independent (Cockburn et al., 2011). It is possible that the induction of CD8 $\mathrm{T}_{\mathrm{E}}$ cells depends on their fine specificity and the site of parasite inoculation. Consequently, CSP-specific CD8 T cells would be induced in the skin draining $\mathrm{LN}$, as sporozoites that are trapped in the skin shed CSP, which could be presented by DCs to T cells. In contrast, LS-Ags, being expressed exclusively in the liver, might activate $\mathrm{T}$ cells in the liver, or be transferred either directly or through liverresident APCs to the liver-draining LNs, to activate T cells there. Owing to the paucity of antigen-specific cells naturally present at the time of immunization or infection, it may not be possible to precisely determine the location of initial priming events.

\section{EFFECTOR LIVER CD8 T CELLS}

$\mathrm{Pb} \gamma$-spz-immune intrahepatic mononuclear cells (IHMC) contain CD4 and CD8 $\mathrm{T}$ cells with inducible CD44 ${ }^{\text {hi }} \mathrm{CD} 25^{\text {hi }}$ and CD45RB ${ }^{\text {lo }}$ phenotypic markers (Guebre-Xabier et al., 1999). Expression of CD45RB, an activation/memory marker, changes from $C D 45 R^{\text {hi }}$ to $C D 45 \mathrm{RB}^{\text {lo }}$ with increased antigen exposure and the state of cellular maturation (Lee et al., 1990; Seder and Ahmed, 2003). Although CD8 CD45RB ${ }^{\text {lo }} \mathrm{T}$ cells are present in naïve liver, multiple immunizations with $\gamma$-spz stabilize and increase the CD45RB ${ }^{\text {lo }}$ (or CD62 $\mathrm{L}^{\text {lo }}$ ) phenotype as well as other phenotypic and functional attributes. For example, enhanced frequencies of CD8 CD45RB ${ }^{\text {lo }} \mathrm{T}$ cells that secrete IFN- $\gamma$ and express KLRG- ${ }^{\text {hi }} \mathrm{CD} 107^{+}$phenotype coincide with the induction of sterile protection (Krzych et al., 2010). These observations are in agreement with the transient expansion of $\mathrm{T}$ cells (Ahmed and Gray, 1996; Badovinac et al., 2002) and the role of CD8 T cells as effectors. 
Liver CD8 $\mathrm{T}$ cells from $\mathrm{Pb} \gamma$-spz-immunized mice produce enhanced IFN $-\gamma 6 \mathrm{~h}$ after challenge and the response peaks around day 7 after challenge (Berenzon et al., 2003). CD8 T cells that produce IFN- $\gamma$ followed by the induction of nitric oxide synthetase (NOS) (Klotz et al., 1995; Doolan and Hoffman, 1999) might be physiologically relevant to the process of elimination of LS parasites: IFN- $\gamma$ inhibits the hepatic stages of rodent and human malaria both in vitro and in vivo (Mellouk et al., 1987); injection of IFN- $\gamma$ protects mice against sporozoite challenge (Ferreira et al., 1986); and immunization with $\gamma$-spz fails to generate protection in IFN- $\gamma \mathrm{R}$ KO mice (Tsuji et al., 1995). Moreover, a reduced IFN- $\gamma$ response from liver CD8 CD $44^{\text {hi }} \mathrm{T}$ cells correlates with decreased protection in mice (Nganou-Makamdop et al., 2012); and Py CS-Tg T cells eliminate the parasite by a mechanism that depends upon rapid IFN- $\gamma$ production (Sano et al., 2001).

Secretion of IFN- $\gamma$ by liver CD8 T cells would preclude the need for direct lysis of hepatocytes, as IFN- $\gamma$ could suppress parasite growth by the few CD8 T cells that encounter infected hepatocytes. IFN $-\gamma$ could also contribute to protection indirectly by upregulating MHC-class I and class II molecules and B7-1 and B7-2 co-stimulatory molecules on $\mathrm{KC}, \mathrm{DC}$, and hepatocytes. This, in turn, would further promote activation of CD8 $\mathrm{T}_{\mathrm{E}}$ cells.

The release of IFN- $\gamma$, which coincides with the activation of CD8 $\mathrm{T}$ cells, is preceded by elevated production of IL-4, which declines when IFN- $\gamma$ reaches its peak (Krzych et al., 2000). The reciprocal regulation between these two cytokines reflects the precise orchestration of functional activities among $\mathrm{T}$ cell subsets induced by $\gamma$-spz. It is likely that IL- 4 in the liver is produced by NK T cells, whereas IFN- $\gamma$ is produced primarily by CD8 $\mathrm{T}$ cells (Berenzon et al., 2003). This view is in agreement with the observation that CD8 $\mathrm{T}_{\mathrm{E}}$ cells decline after inflammation has subsided (Badovinac et al., 2002), whereas memory CD8 $\mathrm{T}$ cells persist, if they are supported by lymphokine-secreting cells.

In our view, sustained protection requires various CD8 T cell specificities, particularly those belonging to proteins expressed during pre-erythrocytic LS development. It could be envisaged that CSP-specific CD8 T cells initiate the effector stage of protection because they are the first cells to produce IFN- $\gamma$ upon encountering infectious sporozoites. Protracted protection might require the subsequent activation of a second wave of CD8 T cells specific for epitopes other than CSP, as they would have to target hepatocytes by recognizing LS-Ags. Such concerted and functionally integrated activity provided by CD8 $\mathrm{T}_{\mathrm{E}}$ cells with multiple specificities might be necessary to provide sustained protection. In their recent study, Butler et al. (2011) propose that GAP parasites arrested during late-LS development induce stronger CD8 $\mathrm{T}$ cell responses and durable protection presumably because these parasites contain a richer repertoire of antigens able to induce effector T cells. Similar observations regarding the availability of a more abundant level of late-LS-Ags have been made in a model system of protection induced by $P$. bergehi sporozoites delivered by the intravenous route under a drug coverage (Nganou-Makamdop et al., 2012).

\section{MEMORY CD8 T CELLS}

The formation of optimally effective memory $T$ cells is an essential feature of an adaptive immune response elicited by infections and it is inextricably linked to long-lasting protective immunity (Ahmed and Gray, 1996). Intrahepatic memory CD8 T cells generated by immunization with $\mathrm{Pb} \gamma$-spz segregate into at least two distinct but developmentally related subsets: the IFN$\gamma$-producing $\mathrm{CD} 44{ }^{\text {hi }} \mathrm{CD} 45 \mathrm{RB}{ }^{\mathrm{lo}} \mathrm{CD} 122^{\text {lo }} \mathrm{CD} 62 \mathrm{~L}^{\text {lo }}$ phenotype, or $\mathrm{T}_{\mathrm{E} / \mathrm{EM}}$ cells, which can be further subdivided based on the expression of IL7R $\alpha$ (CD127) and KLRG-1 into $\mathrm{T}_{\mathrm{E}}\left(\mathrm{CD} 127^{-} \mathrm{KLRG}^{-1^{+}}\right)$ or $\mathrm{T}_{\mathrm{EM}}\left(\mathrm{CD} 127^{+} \mathrm{KLRG}^{-}{ }^{-}\right)$; and the indolent IFN- $\gamma$ producing CD $44{ }^{\text {hi }} \mathrm{CD} 45 \mathrm{RB}^{\mathrm{hi}} \mathrm{CD} 122^{\mathrm{hi}} \mathrm{CD} 62 \mathrm{~L}^{\text {lo/hi }}$ phenotype, hence CD8 $\mathrm{T}_{\mathrm{CM}}$ cells. The elevated expression of CD122 (IL-15R $\alpha$ ) on CD8 $\mathrm{T}_{\mathrm{CM}}$ cells suggests that, in contrast to $\mathrm{CD} 8 \mathrm{~T}_{\mathrm{E} / \mathrm{EM}}$ cells, they are IL-15-dependent (Berenzon et al., 2003; Krzych et al., 2010).

Recently, various phenotypic and functional attributes have been evaluated in an effort to understand the differentiation of memory CD8 T cells (Joshi et al., 2011). In addition, asymmetric division (Ciocca et al., 2012), duration and strength of the TCR signal (D'souza and Hedrick, 2006), and inflammatory cytokines (Obar and Lefrancois, 2010) have been examined as requirements for memory $\mathrm{T}$ cell development and differentiation. Nonetheless, many questions remain regarding the regulation of memory cell formation and in the case of organ-specific infections, like malaria, additional aspects of memory CD8 T cell development and differentiation need to be considered. We propose that these functionally and phenotypically unique subsets of liver memory CD8 T cells form an interactive network involving different phases of dynamic cell activation and differentiation (Berenzon et al., 2003). The copresence of distinct subsets within the intrahepatic memory CD8 $\mathrm{T}$ cell pool in mice protected against malaria is consistent with an earlier view that virally induced memory CD8 T cells are organized into subsets on the basis of distinct functional activities and the maturation/activation status (Sallusto et al., 1999; Kaech et al., 2002; Wherry et al., 2003).

Similar to the rapid responses mediated by influenza- and Sendai-specific CD8 $\mathrm{T}_{\mathrm{E} / \mathrm{EM}}$ cells (Hogan et al., 2001), intrahepatic CD8 $\mathrm{T}_{\mathrm{E} / \mathrm{EM}}$ cells from $\mathrm{Pb} \gamma$-spz-immunized mice produce a copious amount of IFN- $\gamma$ within $1-6 \mathrm{~h}$ after infection. Although the pool of CD8 $\mathrm{T}_{\mathrm{E}}$ cells eventually contracts and the IFN- $\gamma$ response diminishes, the IFN- $\gamma$-producing memory $\mathrm{T}$ cells persist in the livers of mice that maintain protracted protection against a rechallenge (Berenzon et al., 2003; Nganou-Makamdop et al., 2012). A decay of protection is typically accompanied by the decline of IFN- $\gamma$-producing KLRG-1 ${ }^{\text {hi }}$ CD107 ${ }^{\text {hi }}$ CD8 T cells (Krzych et al., 2010).

CD8 $\mathrm{T}_{\mathrm{CM}}$ cells also produce IFN- $\gamma$ but the responses are low and relatively short-lived. Therefore, these cells do not appear to be directly involved in the elimination of the parasite. Instead, by acquiring the $\mathrm{CD} 122^{\text {hi }}$ phenotype, liver CD8 $\mathrm{T}_{\mathrm{CM}}$ cells engage in homeostatic proliferation, which qualifies them to function as a reservoir to maintain the size of memory CD8 T cell pools (Judge et al., 2002; Berenzon et al., 2003; Krzych and Schwenk, 2005). The maintenance of memory pools is one of the prerequisites of a memory $\mathrm{T}$ cell response because attrition, particularly of CD8 $\mathrm{T}_{\mathrm{E}}$ cells, is inevitable during any infection (Badovinac et al., 2002). 


\section{MECHANISMS FOR MAINTENANCE OF PROTECTION INDUCED BY $\gamma$-spz}

Evidence from our laboratory indicates that the persistence of memory CD8 T cells correlates with the maintenance of protective immunity. Interestingly, the persistence of memory phenotype CD8 T cells is restricted to liver lymphocytes, because splenic T cells from the same group of $\gamma$-spz-immunized mice display a phenotype similar to splenic $\mathrm{T}$ cells from naïve mice (Guebre-Xabier et al., 1999).

The persistence of memory CD8 T cells in the liver can be accounted for by several co-existing mechanisms. First, some of the memory $\mathrm{T}$ cells detected after immunization may be longlived memory cells derived from CD8 $\mathrm{T}_{\mathrm{E}}$ cells that survived the contraction phase after sporozoite challenge and have not lost their replicative abilities (Bannard et al., 2009). Second, the CD44 ${ }^{\text {hi }}$ CD45RB ${ }^{\text {lo }}$ CD8 $\mathrm{T}$ cells in the livers of long-term immune mice may be derived from cells that constantly ingress to the liver in response to the liver repository of Plasmodia antigens. The persisting memory may also be derived from naive CD8 T cells that do not quite acquire effector function during priming and subsequent boost immunizations with $\mathrm{Pb} \gamma$-spz. It appears unlikely that they traffic to the liver from the spleen, because CD44 ${ }^{\text {hi }}$ CD8 $\mathrm{T}$ cells are not present in the spleens during protracted immunity; it is possible, however, that they traffic from the draining celiac LNs. Irrespective of whether maintenance of protection relies on long-lived intrahepatic memory $\mathrm{T}$ cells or $\mathrm{T}$ cells that constantly ingress to the liver, both require a repository of Plasmodia antigens (Berenzon et al., 2003).

\section{THE LS-Ag DEPOT IS REQUIRED FOR THE MAINTENANCE OF PROTRACTED PROTECTION}

There is ample contradictory evidence with respect to antigen requirement for the persistence of memory $\mathrm{T}$ cells (Gray and Matzinger, 1991; Murali-Krishna et al., 1999; Jelley-Gibbs et al., 2005; Zammit et al., 2006). On the basis of results from our laboratory, the persistence of a threshold of accumulated LS-Ags is critical for the maintenance of protective immunity. Administration of primaquine at the time of immunization with $\mathrm{Pb} \gamma$-spz does not affect protection at primary challenge, but results in a loss of protracted protection, which correlates with a decrease of CD8 $\mathrm{T}_{\mathrm{E} / \mathrm{EM}}$ cells in the liver. The disruption of the intrahepatic-stage parasite development prevents the formation of a local antigen depot, which impedes the conscription of $\mathrm{T}_{\mathrm{CM}}$ into $\mathrm{T}_{\mathrm{E} / \mathrm{EM}} \mathrm{CD} 8$ $\mathrm{T}$ cells upon re-challenge. In contrast, delayed administration of primaquine has no effect on lasting protective immunity (Berenzon et al., 2003). These results are indeed expected, as the primary action of primaquine is against LS development, without affecting the sporozoite stage, represented by CSP-specific CD8 T cells (Hafalla et al., 2002; Cockburn et al., 2010).

Although most of the results from viral systems argue against the need for antigen to maintain long-lived memory CD8 T cells (Lau et al., 1994; Murali-Krishna et al., 1999), there is evidence that $\mathrm{T}$ cell memory persists if a protracted restimulation of effector $\mathrm{T}$ cells is maintained, either by persisting or by cross-reacting environmental antigens (Zinkernagel et al., 1996; Jelley-Gibbs et al., 2005). We suggest that antigen requirements might be quite different in malaria because the parasite exhibits tropism to the liver, which is characterized by immunologic tolerance. The liver antigen repository may be sufficient to play a unique role in distinguishing the "locally" activated liver memory T cells from those found in the spleen or LN.

The precise location of the LS-Ag depot has not been established. In principle, hepatocytes can function as APC. Although there is no evidence that hepatocytes present LS-Ags to activate or to maintain memory $\mathrm{T}$ cells, because so few hepatocytes become infected by the invading sporozoites and they also are inefficient as APC (Steers et al., 2005), hepatocytes may provide LS-Ag for cross-presentation by either $\mathrm{KC}$ or $\mathrm{CDC}$. It could be envisaged that liver APCs internalize infected hepatocytes and engage in crosspresentation of LS-Ag that gained entry from phagosomes into the MHC-class I pathway. Exogenous particulate Ags were shown to enter the MHC-class I pathway via phagosome-ER fusion (Gagnon et al., 2002) or, as in the case of Toxoplasma gondii, fusion of the parasitophorous vacuole with the ER (Goldszmid et al., 2009).

The mechanism of LS-Ag processing and presentation has not been fully investigated; however, we demonstrated that adoptively transferred liver CD $11 c^{+}$DCs isolated from $\mathrm{Pb} \gamma$-spz-immunized mice confer sterile protection to naive mice during a primary $\mathrm{Pb}$ sporozoite challenge (Jobe et al., 2009). In a recent study, it was shown that proliferation of Py CS-Tg CD8 T cells transferred into Py $\gamma$-spz-immunized mice can be maintained in the liver for up to 60 days post immunization. Depletion of CD11c prior to immunization abolishes this response, which indicates a role for DC as a possible source of CSP depot (Cockburn et al., 2010).

\section{MAINTENANCE OF CENTRAL MEMORY CD8 T CELLS BY IL-15}

It has been established that IL-15 promotes the survival of longterm memory CD8 T cells by maintaining their homeostatic proliferation, whereas IL-2 stimulates both the initial expansion and subsequent contraction of T lymphocytes (Ku et al., 2000; Li et al., 2001; Waldmann et al., 2001; Sprent and Surh, 2002). Although the CD8 $\mathrm{T}_{\mathrm{CM}}$ cell subset represents a much smaller fraction of the liver CD8 $\mathrm{T}$ cells, twice as many CD8 $\mathrm{T}_{\mathrm{CM}}$ cells are CD122 ${ }^{\text {hi }}$ than $\mathrm{T}_{\mathrm{E} / \mathrm{EM}}$ cells, which are primarily CD122 ${ }^{\text {lo }}$ (Berenzon et al., 2003). On the basis of results from in vitro studies, only CD8 $\mathrm{T}_{\mathrm{CM}}$ cells proliferate in the presence of IL-15 and these cells are severely reduced in IL-15KO mice (Krzych et al., 2009). The enhanced sensitivity of the CD8 $\mathrm{T}_{\mathrm{CM}}$ cells to reduced levels of IL-15 suggests that this subset preferentially expand upon exposure to elevated levels of IL-15 in the liver. It also implies that an optimal protective response requires a developmental compartmentalization of CD8 T cells, with each subset performing not only a unique role, but also relying on distinct regulatory mechanisms (Krzych et al., 2009).

We explored the issue of IL-15 as a signal required for the maintenance of memory CD8 T cells in IL-15 deficient mice (Krzych et al., 2009). Like wt mice, IL-15 KO mice are protected against a primary challenge administered shortly after the last boost immunization with $\mathrm{Pb} \gamma$-spz. Protection is short-lived, however, as at re-challenge 2 months later, the IL-15 deficient mice become parasitemic. Analysis of the CD8 T cell subsets at primary challenge show an accumulation of CD8 $\mathrm{T}_{\mathrm{EM}}$ cells and a very small pool of CD8 $\mathrm{T}_{\mathrm{CM}}$ cells. It appears, therefore, that in the absence of IL-15, CD8 $\mathrm{T}_{\mathrm{EM}}$ cells might have developed directly from naïve CD8 $\mathrm{T}$ 
cells as has been shown in other systems (Decaluwe et al., 2010). Without the provision of IL-15, the critical reservoir of memory CD8 T cells is severely reduced and hence unable to sustain a sufficient number of cells needed during re-challenge. We observed a near absence of CD8 $\mathrm{T}_{\mathrm{CM}}$ cells in IL-15 KO mice prior to secondary challenge. The majority of CD8 $\mathrm{T}_{\mathrm{CM}}$ cells undergo severe attrition as evidenced by the level of apoptosis mainly within the CD8 $\mathrm{T}_{\mathrm{CM}}$ cells. Consequently, only $\sim 1 \%$ of the cells remain in IL-15 deficient mice in relation to $\sim 7 \%$ in wt mice. Upon $2^{\circ}$ challenge, the majority of $\mathrm{CD} 127^{\text {hi }} \mathrm{CD} 8 \mathrm{~T}_{\mathrm{CM}}$ cells transition to $\mathrm{CD} 127^{\text {lo }}$ phenotype in wt mice, but in IL-15KO mice few cells become CD127 $7^{\text {lo }}$. These observations strongly support our hypothesis that CD8 $\mathrm{T}_{\mathrm{E} / \mathrm{EM}}$ cells are conscripted from the CD8 $\mathrm{T}_{\mathrm{CM}}$ cells in a continuous, albeit slow, process that occurs in the liver as a result of an increased antigen load after repeated immunizations with $\gamma$-spz. An association between sterile protection and increased antigenic load of late-LS parasites has also been demonstrated in another model system using $\mathrm{Pb}$ sporozoites (Nganou-Makamdop et al., 2012). The conscription of $\mathrm{T}_{\mathrm{E}}$ cells from the $\mathrm{T}_{\mathrm{CM}}$ reservoir also occurs during infection, when large numbers of CD8 $\mathrm{T}_{\mathrm{EM}}$ cells would be most needed to combat the parasite. For example, it has been shown that a large number of $\mathrm{Pb} \mathrm{CS}_{252-260}$-specific CD8 T cells is needed to to maintain sterile protection in $\mathrm{Balb} / \mathrm{c}$ mice challenged with $\mathrm{Pb}$ sporozoites (Schmidt et al., 2011). Compared to many bacterial or viral infections, sterile immunity against malaria infection requires 100-1000 fold higher numbers of CD8 $\mathrm{T}_{\mathrm{E}}$ cells (Schmidt et al., 2008). The requirement for these large numbers of antigen-specific CD8 T cells may be, in part, due to the short time frame of the LS when the parasite is most vulnerable to immune intervention.

In either case, $\mathrm{CD} 8 \mathrm{~T}_{\mathrm{CM}}$ cell pool is maintained in the liver by IL-15. IL-15 is produced by a variety of cell types (although not by $\mathrm{T}$ cells) in response to signaling via TLRs or exposure to type I IFN (Mattei et al., 2001). Pb $\gamma$-spz cause upregulation of IL-15 mRNA in KC (Krzych et al., 2009) and liver cDC (Jobe et al., 2007). Upon encounter with specific antigen from the liver repository or upon re-infections, the CD8 $\mathrm{T}_{\mathrm{CM}}$ cells would be driven to differentiate into the $\mathrm{CD} 44^{\text {hi }} \mathrm{CD} 45 \mathrm{RB}^{\mathrm{lo}} \mathrm{CD} 122^{\text {lo }}$ phenotype that is easily triggered by infectious sporozoites to produce IFN- $\gamma$. Recently, it was demonstrated that CD8 T cell survival during influenza infection is promoted in the lung by trans-presentation of IL-15 by pulmonary CD8 $\alpha^{+}$DCs (McGill et al., 2010). There is evidence (Dubois et al., 2002) that APC retain IL-15 bound to the IL-15R $\alpha$ chain to transactivate CD8 T cells expressing the IL-15R $\beta \gamma$ c complex. On the basis of our previously published results that liver

\section{REFERENCES}

Abdulla, S., Oberholzer, R., Juma, O., Kubhoja, S., Machera, F., Membi, C., et al. (2008). Safety and immunogenicity of RTS,S/AS02D malaria vaccine in infants. N. Engl. J. Med. 359, 2533-2544.

Ahmed, R., and Gray, D. (1996). Immunological memory and protective immunity: understanding their relation. Science 272, 54-60.

Aly, A. S., Lindner, S. E., Mackellar, D. C., Peng, X., and Kappe, S.

cDC activate CD8 T cells in a MHC-class I-dependent manner to express CD44 ${ }^{\text {hi }}$, up-regulate IL-15 mRNA (Jobe et al., 2009) and express detectable IL-15 protein (Krzych et al., 2010), together with KC they can function as APCs of LS-Ags and as trans-presenters of IL-15 that target only liver CD8 $\mathrm{T}_{\mathrm{CM}}$ cells. Our hypothesis is supported by observations from in vitro conducted studies that only CD8 $\mathrm{T}_{\mathrm{CM}}$ cells require trans-presentation of IL-15 in the context of a concurrent signaling via TCR for optimal recall response, as responses by CD8 $\mathrm{T}_{\mathrm{EM}}$ cells are not augmented by IL-15 (Kokaji et al., 2008).

\section{SUMMARY}

MHC-class I-restricted CD8 T cells have been established as key effectors in protective immunity against pre-erythrocytic-stage malaria infection. The effector function is associated mainly with the production of inflammatory cytokines such as IFN- $\gamma$ or TNF$\alpha$ that mediate elimination of the parasite within the hepatocytes by the NO pathway. The success of protection induced by $\gamma$ $\mathrm{spz}$ depends upon the long-lived intrahepatic memory CD8 T cells that consist of developmentally related subsets as CD8 $\mathrm{T}_{\mathrm{CM}}$ and CD8 $\mathrm{T}_{\mathrm{EM}}$ cells. While the CD8 $\mathrm{T}_{\mathrm{EM}}$ cells are maintained by the antigen-driven conscription of the CD8 $\mathrm{T}_{\mathrm{CM}}$ cells, the latter representing a very broad spectrum of antigen-specific $\mathrm{T}$ cells, is maintained by IL-15 and possibly the LS-Ag depot. This arrangement assures a steady availability of antigen-specific T cells should they be required to combat re-infection. The dependence on specific antigen essentially controls the balance between the two phenotypes and the differential expression of IL-15R prevents the CD8 $\mathrm{T}_{\mathrm{EM}}$ cells from becoming activated in the event of sporadic co-infections. However, it is the activated status of the intrahepatic memory CD8 T cells that really distinguishes them from the memory CD8 T cells in the spleen and LN as it represents the sentinel of a local, organ-specific infection.

\section{ACKNOWLEDGMENTS}

The authors would like to express their thanks to all the past and the present members of the Krzych lab. In particular, the authors would like to acknowledge Mr. Isaac Chalom, whose work and dedication during the past decade contributed significantly to the results presented in this review. The authors also acknowledge help and support of Dr. D. Gray Heppner. This research was supported in part by a grant from the National Institutes of Health (UK) and the US Army Materiel Command. The views of the authors do not purport to reflect the position of the Department of the Army or the Department of Defense.

Bejon, P., Mwacharo, J., Kai, O., Todryk, S., Keating, S., Lowe, B., et al. (2007). The induction and persistence of T cell IFN-gamma responses after vaccination or natural exposure is suppressed by Plasmodium falciparum. J. Immunol. 179, 4193-4201.

Belz, G. T., Smith, C. M., Kleinert, L., Reading, P., Brooks, A., Shortman, K., et al. (2004). Distinct migrating and nonmigrating dendritic cell populations are involved in $\mathrm{MHC}$ class I-restricted antigen presentation after lung infection with virus. Proc. Natl. Acad. Sci. U.S.A. 101 8670-8675.

Berenzon, D., Schwenk, R. J., Letellier, L., Guebre-Xabier, M., Williams, J., and Krzych, U. (2003). Protracted protection to Plasmodium berghei malaria is linked to functionally and phenotypically heterogeneous liver memory CD8+ $\mathrm{T}$ cells. J. Immunol. 171, 2024-2034. 
Bertolino, P., Bowen, D. G., Mccaughan, G. W., and Fazekas De St Groth, B. (2001). Antigen-specific primary activation of CD8 $+\mathrm{T}$ cells within the liver. J. Immunol. 166, 5430-5438.

Bongfen, S. E., Torgler, R., Romero, J. F., Renia, L., and Corradin, G. (2007). Plasmodium berghei-infected primary hepatocytes process and present the circumsporozoite protein to specific CD8+ T cells in vitro. J. Immunol. 178, 7054-7063.

Bucci, K., Kastens, W., Hollingdale, M. R., Shankar, A., Alpers, M. P., King, C. L., et al. (2000). Influence of age and HLA type on interferon-gamma (IFN-gamma) responses to a naturally occurring polymorphic epitope of Plasmodium falciparum liver stage antigen-1 (LSA-1). Clin. Exp. Immunol. 122, 94-100.

Butler, N. S., Schmidt, N. W., Vaughan, A. M., Aly, A. S., Kappe, S. H., and Harty, J. T. (2011). Superior antimalarial immunity after vaccination with late liver stage-arresting genetically attenuated parasites. Cell Host Microbe 9, 451-462.

Cervi, L., Macdonald, A. S., Kane, C., Dzierszinski, F., and Pearce, E. J. (2004). Cutting edge: dendritic cells copulsed with microbial and helminth antigens undergo modified maturation, segregate the antigens to distinct intracellular compartments, and concurrently induce microbe-specific Th1 and helminthspecific Th2 responses. J. Immunol. 172, 2016-2020.

Chakravarty, S., Cockburn, I. A., Kuk, S., Overstreet, M. G., Sacci, J. B., and Zavala, F. (2007). CD8+ T lymphocytes protective against malaria liver stages are primed in skindraining lymph nodes. Nat. Med. 13, 1035-1041.

Ciocca, M. L., Barnett, B. E., Burkhardt, J. K., Chang, J. T., and Reiner, S. L. (2012). Cutting edge: asymmetric memory $\mathrm{T}$ cell division in response to rechallenge. J. Immunol. 188, 4145-4148.

Clyde, D. F., Most, H., Mccarthy, V. C., and Vanderberg, J. P. (1973). Immunization of man against sporoziteinduced falciparum malaria. Am. J. Med. Sci. 266, 169-177.

Cockburn, I. A., Chen, Y. C., Overstreet, M. G., Lees, J. R., Van Rooijen, N., Farber, D. L., et al. (2010). Prolonged antigen presentation is required for optimal CD8 $+\mathrm{T}$ cell responses against malaria liver stage parasites. PLoS Pathog. 6:e1000877. doi:10.1371/journal.ppat.1000877

Cockburn, I. A., Tse, S. W., Radtke, A. J., Srinivasan, P., Chen, Y. C.,
Sinnis, P., et al. (2011). Dendritic cells and hepatocytes use distinct pathways to process protective antigen from plasmodium in vivo. PLoS Pathog 7:e1001318. doi:10.1371/journal.ppat.1001318

Crispe, I. N. (2011). Liver antigenpresenting cells. J. Hepatol. 54, 357-365.

Decaluwe, H., Taillardet, M., Corcuff, E., Munitic, I., Law, H. K., Rocha, B., et al. (2010). Gamma(c) deficiency precludes $\mathrm{CD} 8+\mathrm{T}$ cell memory despite formation of potent $\mathrm{T}$ cell effectors. Proc. Natl. Acad. Sci. U.S.A. 107, 9311-9316.

Doolan, D. L., and Hoffman, S. L. (1999). IL-12 and NK cells are required for antigen-specific adaptive immunity against malaria initiated by CD8+ $\mathrm{T}$ cells in the Plasmodium yoelii model. J. Immunol. 163, 884-892.

Doolan, D. L., Southwood, S., Freilich, D. A., Sidney, J., Graber, N. L., Shatney, L., et al. (2003). Identification of Plasmodium falciparum antigens by antigenic analysis of genomic and proteomic data. Proc. Natl. Acad. Sci. U.S.A. 100, 9952-9957.

D'souza, W. N., and Hedrick, S. M. (2006). Cutting edge: latecomer CD8 $\mathrm{T}$ cells are imprinted with a unique differentiation program. J. Immunol. 177, 777-781.

Dubois, S., Mariner, J., Waldmann, T.A., and Tagaya, Y. (2002). IL-15R alpha recycles and presents IL-15 In trans to neighboring cells. Immunity 17, 537-547.

Egan, J. E., Hoffman, S. L., Haynes, J. D., Sadoff, J. C., Schneider, I., Grau, G. E., et al. (1993). Humoral immune responses in volunteers immunized with irradiated Plasmodium falciparum sporozoites. Am. J. Trop. Med. Hyg. 49, 166-173.

Ferreira, A., Schofield, L., Enea, V., Schellekens, H., Van Der Meide, P., Collins, W. E., et al. (1986). Inhibition of development of exoerythrocytic forms of malaria parasites by gamma-interferon. Science 232, 881-884.

Fidock, D. A., Gras-Masse, H., Lepers, J. P., Brahimi, K., Benmohamed, L., Mellouk, S., et al. (1994). Plasmodium falciparum liver stage antigen-1 is well conserved and contains potent $\mathrm{B}$ and $\mathrm{T}$ cell determinants. J. Immunol. 153, 190-204.

Fidock, D. A., Pasquetto, V., Gras, H., Badell, E., Eling, W., Ballou, W. R., et al. (1997). Plasmodium falciparum sporozoite invasion is inhibited by naturally acquired or experimentally induced polyclonal antibodies to the
STARP antigen. Eur. J. Immunol. 27, 2502-2513.

Frevert, U. (1994). Malaria sporozoitehepatocyte interactions. Exp. Parasitol. 79, 206-210.

Gagnon, E., Duclos, S., Rondeau, C., Chevet, E., Cameron, P. H., Steele-Mortimer, O., et al. (2002). Endoplasmic reticulum-mediated phagocytosis is a mechanism of entry into macrophages. Cell 110 119-131.

Goldszmid, R. S., Coppens, I., Lev, A., Caspar, P., Mellman, I., and Sher, A. (2009). Host ER-parasitophorous vacuole interaction provides a route of entry for antigen cross-presentation in Toxoplasma gondii-infected dendritic cells. J. Exp. Med. 206, 399-410.

Good, M. F., Xu, H., Wykes, M., and Engwerda, C. R. (2005). Development and regulation of cellmediated immune responses to the blood stages of malaria: implications for vaccine research. Annu. Rev. Immunol. 23, 69-99.

Gray, D., and Matzinger, P. (1991). T cell memory is short-lived in the absence of antigen. J. Exp. Med. 174, 969-974.

Guebre-Xabier, M., Schwenk, R., and Krzych, U. (1999). Memory phenotype CD8(+) $\mathrm{T}$ cells persist in livers of mice protected against malaria by immunization with attenuated Plasmodium berghei sporozoites. Eur. J. Immunol. 29, 3978-3986.

Hafalla, J. C., Sano, G., Carvalho, L. H., Morrot, A., and Zavala, F. (2002). Short-term antigen presentation and single clonal burst limit the magnitude of the CD8(+) $\mathrm{T}$ cell responses to malaria liver stages. Proc. Natl. Acad. Sci. U.S.A. 99, 11819-11824.

Hill, A. V., Allsopp, C. E., Kwiatkowski, D., Anstey, N. M., Twumasi, P., Rowe, P. A., et al. (1991). Common west African HLA antigens are associated with protection from severe malaria. Nature 352, 595-600.

Hoffman, S. L., Goh, L. M., Luke, T. C., Schneider, I., Le, T. P., Doolan, D. L., et al. (2002). Protection of humans against malaria by immunization with radiation-attenuated Plasmodium falciparum sporozoites. J. Infect. Dis. 185, 1155-1164.

Hogan, R. J., Usherwood, E. J., Zhong, W., Roberts, A. A., Dutton, R. W., Harmsen, A. G., et al. (2001). Activated antigen-specific CD8+ T cells persist in the lungs following recovery from respiratory virus infections. J. Immunol. 166, 1813-1822.

Holder, A. A. (1996). "Preventing merozoite invasion of erythrocytes," in
Malaria Vaccine Development: A Multi-Immune Response Approach, ed. S. L. Hoffman (Washington, DC: ASM Press), 77-92.

Hollingdale, M. R., and Krzych, U. (2002). Immune responses to liver-stage parasites: implications for vaccine development. Chem. Immunol. 80, 97-124.

Jelley-Gibbs, D. M., Brown, D. M., Dibble, J. P., Haynes, L., Eaton, S. M., and Swain, S. L. (2005). Unexpected prolonged presentation of influenza antigens promotes CD4 T cell memory generation. J. Exp. Med. 202, 697-706.

Jobe, O., Donofrio, G., Sun, G., Liepinsh, D., Schwenk, R., and Krzych, U. (2009). Immunization with radiation-attenuated Plasmodium berghei sporozoites induces liver cCD8alpha+ DC that activate $\mathrm{CD} 8+\mathrm{T}$ cells against liverstage malaria. PLoS ONE 4:e5075. doi:10.1371/journal.pone.0005075

Jobe, O., Lumsden, J., Mueller, A. K., Williams, J., Silva-Rivera, H., Kappe, S. H., et al. (2007). Genetically attenuated Plasmodium berghei liver stages induce sterile protracted protection that is mediated by major histocompatibility complex Class I-dependent interferon-gammaproducing CD8+ $\mathrm{T}$ cells. J. Infect. Dis. 196, 599-607.

Joshi, N. S., Cui, W., Dominguez, C. X., Chen, J. H., Hand, T. W., and Kaech, S. M. (2011). Increased numbers of preexisting memory CD8 $\mathrm{T}$ cells and decreased T-bet expression can restrain terminal differentiation of secondary effector and memory CD8 T cells. J. Immunol. 187, 4068-4076.

Judge, A. D., Zhang, X., Fujii, H., Surh, C. D., and Sprent, J. (2002). Interleukin 15 controls both proliferation and survival of a subset of memoryphenotype CD8(+) T cells. J. Exp. Med. 196, 935-946.

Kaech, S. M., Wherry, E. J., and Ahmed, R. (2002). Effector and memory T-cell differentiation: implications for vaccine development. Nat. Rev. Immunol. 2, 251-262.

Khan, S., Van Den Broek, M., Schwarz, K., De Giuli, R., Diener, P. A., and Groettrup, M. (2001). Immunoproteasomes largely replace constitutive proteasomes during an antiviral and antibacterial immune response in the liver. J. Immunol. 167, 6859-6868.

Klein, I., and Crispe, I. N. (2006). Complete differentiation of CD8+ $\mathrm{T}$ cells activated locally within the transplanted liver. J. Exp. Med. 203, 437-447. 
Klotz, F. W., Scheller, L. F., Seguin, M. C., Kumar, N., Marletta, M. A., Green, S. J., et al. (1995). Co-localization of inducible-nitric oxide synthase and Plasmodium berghei in hepatocytes from rats immunized with irradiated sporozoites. J. Immunol. 154, 3391-3395.

Kokaji, A. I., Hockley, D. L., and Kane, K. P. (2008). IL-15 transpresentation augments CD8+ $\mathrm{T}$ cell activation and is required for optimal recall responses by central memory CD $8+$ T cells. J. Immunol. 180, 4391-4401.

Krzych, U. (1999). "Malaria and the liver: tolerance and immunity to attenuated Plasmodia sporozoites," in $T$ Lymphocytes in the Liver: Immunobiology, Pathology and Host Defense, ed. I. N. Crispe (New York: Wiley-Liss), 163-195.

Krzych, U., Dalai, S., Ehrler, L., Jobe, O., and Egner, L. (2010). Infectious challenge of Plasmodium berghei $\gamma$ spz immunized mice rescues effector $\mathrm{CD} 8+\mathrm{T}$ cells, thus assuring protracted protection. J. Immunol. 184, 52.9 , abstr.

Krzych, U., Lyon, J. A., Jareed, T., Schneider, I., Hollingdale, M. R., Gordon, D. M., et al. (1995). T lymphocytes from volunteers immunized with irradiated Plasmodium falciparum sporozoites recognize liver and blood stage malaria antigens. $J$. Immunol. 155, 4072-4077.

Krzych, U., and Schwenk, J. (2005). The dissection of CD8 T cells during liver-stage infection. Curr. Top. Microbiol. Immunol. 297, 1-24.

Krzych, U., Schwenk, R., Guebre-Xabier, M., Sun, P., Palmer, D., White, K., et al. (2000). The role of intrahepatic lymphocytes in mediating protective immunity induced by attenuated Plasmodium berghei sporozoites. Immunol. Rev. 174, 123-134.

Krzych, U., Steers, N., Lumsden, J., Berenzon, D., Liepinsh, D., and Schwenk, R. (2009). IL-15 maintains a reservoir of central memory CD8 $\mathrm{T}$ cells that are required for protracted protection against Plasmodium berghei infection. Am. J. Trop. Med. Hyg. 81, 739, abstr.

Ku, C. C., Murakami, M., Sakamoto, A., Kappler, J., and Marrack, P. (2000). Control of homeostasis of CD8+ memory $\mathrm{T}$ cells by opposing cytokines. Science 288, 675-678.

Langhorne, J., Ndungu, F. M., Sponaas, A. M., and Marsh, K. (2008). Immunity to malaria: more questions than answers. Nat. Immunol. 9 , 725-732.

Lau, L. L., Jamieson, B. D., Somasundaram, T., and Ahmed, R. (1994).
Cytotoxic T-cell memory without antigen. Nature 369, 648-652.

Lee, W. T., Yin, X. M., and Vitetta, E. S. (1990). Functional and ontogenetic analysis of murine CD45Rhi and CD45Rlo CD4+ T cells. J. Immunol. 144, 3288-3295.

Li, X. C., Demirci, G., Ferrari-Lacraz, S., Groves, C., Coyle, A., Malek, T. R., et al. (2001). IL-15 and IL-2: a matter of life and death for $\mathrm{T}$ cells in vivo. Nat. Med. 7, 114-118.

Malik, A., Egan, J. E., Houghten, R. A., Sadoff, J. C., and Hoffman, S. L. (1991). Human cytotoxic T lymphocytes against the Plasmodium falciparum circumsporozoite protein. Proc. Natl. Acad. Sci. U.S.A. 88, 3300-3304.

Mattei, F., Schiavoni, G., Belardelli, F., and Tough, D. F. (2001). IL-15 is expressed by dendritic cells in response to type I IFN, doublestranded RNA, or lipopolysaccharide and promotes dendritic cell activation. J. Immunol. 167, 1179-1187.

Matzinger, P. (1994). Tolerance, danger, and the extended family. Annu. Rev. Immunol. 12, 991-1045.

McGill, J., Van Rooijen, N., and Legge, K. L. (2010). IL-15 trans-presentation by pulmonary dendritic cells promotes effector CD8 $\mathrm{T}$ cell survival during influenza virus infection. $J$. Exp. Med. 207, 521-534.

Mehal, W. Z., Juedes, A. E., and Crispe, I. N. (1999). Selective retention of activated CD8 $+\mathrm{T}$ cells by the normal liver. J. Immunol. 163, 3202-3210.

Mellouk, S., Maheshwari, R. K., RhodesFeuillette, A., Beaudoin, R. L., Berbiguier, N., Matile, H., et al. (1987). Inhibitory activity of interferons and interleukin 1 on the development of Plasmodium falciparum in human hepatocyte cultures. J. Immunol. 139, 4192-4195.

Mueller, A. K., Camargo, N., Kaiser, K., Andorfer, C., Frevert, U., Matuschewski, K., et al. (2005). Plasmodium liver stage developmental arrest by depletion of a protein at the parasite-host interface. Proc. Natl. Acad. Sci. U.S.A. 102, 3022-3027.

Mueller, A. K., Deckert, M., Heiss, K., Goetz, K., Matuschewski, K., and Schluter, D. (2007). Genetically attenuated Plasmodium berghei liver stages persist and elicit sterile protection primarily via CD8 T cells. Am. J. Pathol. 171, 107-115.

Murali-Krishna, K., Lau, L. L., Sambhara, S., Lemonnier, F., Altman, J., and Ahmed, R. (1999). Persistence of memory CD8 $\mathrm{T}$ cells in MHC class I-deficient mice. Science 286, 1377-1381.

Nardin, E. H., Herrington, D. A., Davis, J., Levine, M., Stuber, D., Takacs, B., et al. (1989). Conserved repetitive epitope recognized by $\mathrm{CD} 4+$ clones from a malaria-immunized volunteer. Science 246, 1603-1606.

Nardin, E. H., and Nussenzweig, R. S. (1993). T cell responses to preerythrocytic stages of malaria: role in protection and vaccine development against pre-erythrocytic stages. Annu. Rev. Immunol. 11, 687-727.

Nganou-Makamdop, K., Van Gemert, G. J., Arens, T., Hermsen, C. C., and Sauerwein, R. W. (2012). Long term protection after immunization with P. berghei sporozoites correlates with sustained IFN gamma responses of hepatic $\mathrm{CD} 8+$ memory $\mathrm{T}$ cells. PLoS ONE 7:e36508. doi:10.1371/journal.pone.0036508

Nussenzweig, R. S., Vanderberg, J., Most, H., and Orton, C. (1967). Protective immunity produced by the injection of x-irradiated sporozoites of Plasmodium berghei. Nature 216, 160-162.

Nussenzweig, R. S., Vanderberg, J., Most, H., and Orton, C. (1970). Immunity in simian malaria induced by irradiated sporozoites. J. Parasitol. 56, 350-351.

Obar, J. J., and Lefrancois, L. (2010). Early signals during CD8 $\mathrm{T}$ cell priming regulate the generation of central memory cells. J. Immunol. 185, 263-272.

Palmer, D. R., and Krzych, U. (2002). Cellular and molecular requirements for the recall of IL-4-producing memory $\mathrm{CD} 4(+) \mathrm{CD} 45 \mathrm{RO}(+) \mathrm{CD} 27(-)$

$\mathrm{T}$ cells during protection induced by attenuated Plasmodium falciparum sporozoites. Eur. J. Immunol. 32, 652-661.

Plebanski, M., Lee, E. A., Hannan, C. M., Flanagan, K. L., Gilbert, S. C., Gravenor, M. B., et al. (1999). Altered peptide ligands narrow the repertoire of cellular immune responses by interfering with T-cell priming. Nat. Med. 5, 565-571.

Pradel, G., and Frevert, U. (2001). Malaria sporozoites actively enter and pass through rat Kupffer cells prior to hepatocyte invasion. Hepatology 33, 1154-1165.

Prudencio, M., Rodriguez, A., and Mota, M. M. (2006). The silent path to thousands of merozoites: the Plasmodium liver stage. Nat. Rev. Microbiol. 4, 849-856.

Robson, K. J., Frevert, U., Reckmann, I., Cowan, G., Beier, J., Scragg, I.
G., et al. (1995). Thrombospondinrelated adhesive protein (TRAP) of Plasmodium falciparum: expression during sporozoite ontogeny and binding to human hepatocytes. EMBO J. 14, 3883-3894.

Rodrigues, M., Nussenzweig, R. S., Romero, P., and Zavala, F. (1992). The in vivo cytotoxic activity of $\mathrm{CD} 8+\mathrm{T}$ cell clones correlates with their levels of expression of adhesion molecules. J. Exp. Med. 175, 895-905.

Rogers, W. O., Malik, A., Mellouk, S., Nakamura, K., Rogers, M. D., Szarfman, A., et al. (1992). Characterization of Plasmodium falciparum sporozoite surface protein 2. Proc. Natl. Acad. Sci. U.S.A. 89, 9176-9180.

Sallusto, F., Lenig, D., Forster, R., Lipp, M., and Lanzavecchia, A. (1999) Two subsets of memory T lymphocytes with distinct homing potentials and effector functions. Nature 401, 708-712.

Sano, G., Hafalla, J. C., Morrot, A., Abe, R., Lafaille, J. J., and Zavala, F. (2001). Swift development of protective effector functions in naive CD8(+) T cells against malaria liver stages. J. Exp. Med. 194, 173-180.

Scheller, L. F., and Azad, A. F. (1995). Maintenance of protective immunity against malaria by persistent hepatic parasites derived from irradiated sporozoites. Proc. Natl. Acad. Sci. U.S.A. 92, 4066-4068.

Schmidt, N. W., Butler, N. S., and Harty, J. T. (2011). Plasmodium-host interactions directly influence the threshold of memory CD8 $\mathrm{T}$ cells required for protective immunity. J. Immunol. 186, 5873-5884.

Schmidt, N. W., Podyminogin, R. L., Butler, N. S., Badovinac, V. P., Tucker, B. J., Bahjat, K. S., et al. (2008). Memory $\mathrm{CD} 8 \mathrm{~T}$ cell responses exceeding a large but definable threshold provide long-term immunity to malaria. Proc. Natl. Acad. Sci. U.S.A. 105, 14017-14022.

Schofield, L., Villaquiran, J., Ferreira, A., Schellekens, H., Nussenzweig, R., and Nussenzweig, V. (1987). Gamma interferon, CD8+ T cells and antibodies required for immunity to malaria sporozoites. Nature 330, 664-666.

Sedegah, M., Finkelman, F., and Hoffman, S. L. (1994). Interleukin 12 induction of interferon gamma-dependent protection against malaria. Proc. Natl. Acad. Sci. U.S.A. 91, 10700-10702.

Seder, R. A., and Ahmed, R. (2003). Similarities and differences in CD4+ and $\mathrm{CD} 8+$ effector and memory 
T cell generation. Nat. Immunol. 4, 835-842.

Seguin, M. C., Klotz, F. W., Schneider, I., Weir, J. P., Goodbary, M., Slayter, M., et al. (1994). Induction of nitric oxide synthase protects against malaria in mice exposed to irradiated Plasmodium berghei infected mosquitoes: involvement of interferon gamma and CD8+ T cells. J. Exp. Med. 180, 353-358.

Silvie, O., Franetich, J. F., Charrin, S., Mueller, M. S., Siau, A., Bodescot, M., et al. (2004). A role for apical membrane antigen 1 during invasion of hepatocytes by Plasmodium falciparum sporozoites. J. Biol. Chem. 279, 9490-9496.

Sprent, J., and Surh, C. D. (2002). T cell memory. Annu. Rev. Immunol. 20, 551-579.

Steers, N., Schwenk, R., Bacon, D. J., Berenzon, D., Williams, J., and Krzych, U. (2005). The immune status of Kupffer cells profoundly influences their responses to infectious Plasmodium berghei sporozoites. Eur. J. Immunol. 35, 2335-2346.

Tarun, A. S., Dumpit, R. F., Camargo, N., Labaied, M., Liu, P., Takagi, A., et al. (2007). Protracted sterile protection with Plasmodium yoelii preerythrocytic genetically attenuated parasite malaria vaccines is independent of significant liver-stage persistence and is mediated by CD8+ T cells. J. Infect. Dis. 196, 608-616.

Teirlinck, A. C., Mccall, M. B., Roestenberg, M., Scholzen, A., Woestenenk,
R., De Mast, Q., et al. (2011). Longevity and composition of cellular immune responses following experimental Plasmodium falciparum malaria infection in humans. PLoS Pathog. 7:e1002389. doi:10.1371/journal.ppat.1002389

Trimnell, A., Takagi, A., Gupta, M., Richie, T. L., Kappe, S. H., and Wang, R. (2009). Genetically attenuated parasite vaccines induce contactdependent $\mathrm{CD} 8+\mathrm{T}$ cell killing of Plasmodium yoelii liver stageinfected hepatocytes. J. Immunol. $183,5870-5878$.

Tsuji, M., Miyahira, Y., Nussenzweig, R. S., Aguet, M., Reichel, M., and Zavala, F. (1995). Development of antimalaria immunity in mice lacking IFN-gamma receptor. J. Immunol. 154, 5338-5344.

Urban, B. C., Ing, R., and Stevenson, M. M. (2005). Early interactions between blood-stage plasmodium parasites and the immune system. Curr. Top. Microbiol. Immunol. 297, 25-70.

Vaughan, A. M., O'neill, M. T., Tarun, A. S., Camargo, N., Phuong, T. M., Aly, A. S., et al. (2009). Type II fatty acid synthesis is essential only for malaria parasite late liver stage development. Cell. Microbiol. 11, 506-520.

Waldmann, T. A., Dubois, S., and Tagaya, Y. (2001). Contrasting roles of IL-2 and IL-15 in the life and death of lymphocytes: implications for immunotherapy. Immunity 14, 105-110.
Weiss, W. R., Sedegah, M., Beaudoin, R. L., Miller, L. H., and Good, M. F. (1988). CD8+ T cells (cytotoxic/suppressors) are required for protection in mice immunized with malaria sporozoites. Proc. Natl. Acad. Sci. U.S.A. 85, 573-576.

Wherry, E. J., Teichgraber, V., Becker, T. C., Masopust, D., Kaech, S. M., Antia, R., et al. (2003). Lineage relationship and protective immunity of memory CD8 T cell subsets. Nat. Immunol. 4 225-234.

White, K. L., Snyder, H. L., and Krzych, U. (1996). MHC class Idependent presentation of exoerythrocytic antigens to CD8+ T lymphocytes is required for protective immunity against Plasmodium berghei. J. Immunol. 156, 3374-3381.

Wizel, B., Houghten, R. A., Parker, K. C., Coligan, J. E., Church, P., Gordon, D. M., et al. (1995). Irradiated sporozoite vaccine induces HLA-B8restricted cytotoxic $\mathrm{T}$ lymphocyte responses against two overlapping epitopes of the Plasmodium falciparum sporozoite surface protein 2 . J. Exp. Med. 182, 1435-1445.

Zammit, D. J., Turner, D. L., Klonowski, K. D., Lefrancois, L., and Cauley, L. S. (2006). Residual antigen presentation after influenza virus infection affects CD8 $\mathrm{T}$ cell activation and migration. Immunity 24, 439-449.

Zechini, B., Cordier, L., Ngonseu, E., D'alessandro, U., Wery, M., and Chatterjee, S. (1999). Plasmodium berghei development in irradiated sporozoite-immunized C57BL6 mice. Parasitology $118(\mathrm{Pt} \quad 4)$, 335-338.

Zinkernagel, R. M., Bachmann, M. F., Kundig, T. M., Oehen, S., Pirchet, H., and Hengartner, H. (1996). On immunological memory. Annu. Rev. Immunol. 14, 333-367.

Conflict of Interest Statement: The authors declare that the research was conducted in the absence of any commercial or financial relationships that could be construed as a potential conflict of interest.

Received: 30 September 2012; paper pending published: 17 October 2012; accepted: 20 November 2012; published online: 10 December 2012.

Citation: Krzych U, Dalai S, Zarling S and Pichugin A (2012) Memory CD8 $T$ cells specific for Plasmodia liver-stage antigens maintain protracted protection against malaria. Front. Immun. 3:370. doi: 10.3389/fimmu.2012.00370

This article was submitted to Frontiers in Immunological Memory, a specialty of Frontiers in Immunology.

Copyright (๑) 2012 Krzych, Dalai, Zarling and Pichugin. This is an open-access article distributed under the terms of the Creative Commons Attribution License, which permits use, distribution and reproduction in other forums, provided the original authors and source are credited and subject to any copyright notices concerning any third-party graphics etc. 